\title{
Resilience Factors in Women with Severe Early-Life Maltreatment
}

\author{
Karen Hillmann ${ }^{\mathrm{a}} \quad$ Corinne Neukel $^{\mathrm{a}} \quad$ Dirk Hagemann $^{\mathrm{b}}$ Sabine C. Herpertz ${ }^{\mathrm{a}}$ \\ Katja Bertsch ${ }^{\mathrm{a}}$ \\ a Department of General Psychiatry, Center for Psychosocial Medicine, University of Heidelberg, and ${ }^{\text {b Section of }}$ \\ Personality Psychology, Institute of Psychology, Ruprecht Karls University of Heidelberg, Heidelberg, Germany
}

\section{Key Words}

Psychopathology · Risk factors · Violence · Protective factors - Trauma - Physical and sexual abuse $\cdot$ Childhood . Mental health

\begin{abstract}
Introduction: Early-life maltreatment (ELM) has long-lasting negative consequences and is the most important general risk factor for mental disorders. Nevertheless, a number of maltreated children grow up to become healthy adults and have therefore been called 'resilient'. The aim of the current study is to investigate 'resilience factors' in the context of severe ELM. Method: The study was part of the large multicenter project Understanding and Breaking the Intergenerational Cycle of Abuse (UBICA). A total of 89 women were examined, 33 with ELM and at least one lifetime mental disorder (nonresilient), 19 with ELM but without lifetime mental disorders (resilient), and 37 without ELM and without lifetime mental disorders (controls). ELM and other circumstances before the age of 18 years were assessed with the Childhood Experience of Care and Abuse (CECA) Interview. Additional relevant person and situation factors were measured with the Structured Clinical Interview for Mental Disorders (SCID-I), International Personality Disorder Exam-
\end{abstract}

ination (IPDE), Difficulties in Emotion Regulation Scale (DERS), Vulnerable Attachment Style Questionnaire (VASQ), Barratt Impulsiveness Scale (BIS), NEO Five-Factor Inventory (NEO-FFI), and Multiple-Choice Vocabulary Intelligence Test (MWT-B). Factor analyses and paired $t$ tests were performed to identify those variables which differentiate best between the three groups. In addition, a discriminant analysis was conducted to detect the accuracy of assigning women to their specific group. Results: The factor analyses revealed 10 resilience factors based on which we could correctly assign $80 \%$ of the women to their group in the discriminant analysis. $t$ tests of factor scores showed that resilient and nonresilient maltreated women mainly differed in current individual attributes (e.g. impulsivity, attachment style), while resilient and nonresilient maltreated women differed from controls in both their current individual attributes and their view of their situation as a child. Conclusion: The 4 variables neuroticism, extraversion, vulnerable attachment, and perceived loneliness during childhood were identified as most important in differentiating all three examined groups. Therefore, prevention and intervention programs focusing on the individual's development of secure attachment and social competence may be of particular importance in the context of ELM.

(c) 2016 S. Karger AG, Base

\section{KARGER}

E-Mail karger@karger.com

www.karger.com/psp
C 2016 S. Karger AG, Basel

0254-4962/16/0494-0261\$39.50/0
Karen Hillmann

Department of General Psychiatry, Center for Psychosocial Medicine University of Heidelberg, Vossstrasse 4 DE-69115 Heidelberg (Germany)

E-Mail karen.hillmann@med.uni-heidelberg.de 


\section{Introduction}

Early-life maltreatment (ELM) is highly prevalent. In a large representative German sample, $12.0 \%$ of participants reported physical maltreatment and $12.6 \%$ sexual maltreatment, which were of severe intensity in $2.8 \%$ (1.9\% for sexual maltreatment) [1]. There is accumulating evidence that experiences of ELM are the most important general risk factor for the development of various mental disorders [2], with severe and lasting negative consequences for the maltreated individual [3]. Nevertheless, there are a number of individuals who have experienced severe forms of ELM but do not develop any mental disorder, and who are thus regarded as 'resilient'. According to Luthar et al. [4], individuals may be regarded as resilient if they have endured some kind of adversity, such as ELM, and have experienced a positive adaptation after the adversity. In the current study, we defined adversity as an experience of severe sexual or physical maltreatment before the age of 18 years (for a similar definition of adversity, see Jaffee [5]), while the positive adaptation is seen as the absence of a lifetime mental disorder in middle adulthood. This is also in line with the resilience model by Richardson [6], which describes four possible outcomes of reintegration after an adversity: first, a resilient reintegration referring to a positive adaptation or personal growth as a result of overcoming disruptive life events such as ELM and an improvement of resilient qualities or so-called protective factors; second, a reintegration back to homeostasis, describing individuals getting past the disruption by avoiding introspection; third, a reintegration with loss, where hope, motivation, or drive is given up or resilient qualities decrease due to a disruptive life event, and fourth, a dysfunctional reintegration referring to destructive behaviors or introversive disorders as consequences of adversities.

In the last decade, researchers have started to investigate factors that protect individuals from developing mental disorders [7], so-called 'resilience factors'. Luthar et al. [4] organized important resilience factors into three main categories: individual attributes, aspects of the individual's childhood family, and characteristics of the individual's wider social environment during childhood. The main goal of the current study was to identify specific variables that may differentiate women with experiences of sexual or physical ELM but have not developed any mental disorder (resilient women) from those who have had such experiences but do have a history of mental disorder (nonresilient women) and from a nonmaltreated group of women without a history of mental disorder (controls). We therefore collected self-report and interview-based data on 18 variables, which have been previously identified as possible resilience factors within the three above-mentioned categories [4]. With regard to individual attributes, greater intelligence $[8,9]$, education as a reflection of higher achievement orientation [10], low levels of loneliness [11], shyness [12], feelings of inferiority [13], impulsivity [14], emotion dysregulation [15], and neuroticism $[7,16,17]$, but high levels of extraversion [7, $16,17]$ and a secure attachment style [18] have been related to resilience and mental well-being. In addition, parental occupation and income have been shown to be resilience factors on the level of the individual's childhood family [19], while no significant associations have been found between resilience and household stability [20] or family size [7]. In the wider social environment during childhood, the ability to recruit support outside the family $[21,22]$, contact with other community groups [23], and peer relationships [7] have been found to be of particular importance regarding resilience.

We expected to find the factor structure hypothesized by Luthar et al. [4] in our resilience factors. We hypothesized that nonresilient women significantly differ from resilient women in the measured resilience factors in addition to differing from healthy controls (HC). Furthermore, we assumed that resilient women do not differ from $\mathrm{HC}$ in the resilience factors. We expected that we would be able to assign women to the correct group (nonresilient, resilient, or $\mathrm{HC}$ ) using the resilience factors as predictors in a discriminant analysis.

\section{Method}

\section{Participants}

The study was part of a large multicenter project, which investigated the intergenerational transmission of ELM (Understanding and Breaking the Intergenerational Cycle of Abuse, UBICA). Please note that there may be overlaps between the samples of the current study and other studies which originate from the UBICA consortium. The final sample $(n=89)$ comprised 33 women with experiences of ELM who had developed a lifetime mental disorder (nonresilient: mean age $=38.67, \mathrm{SD}=5.86$ years), 19 women with experiences of ELM who had not developed a lifetime mental disorder (resilient: mean age $=39.37, \mathrm{SD}=6.27$ years) and 37 women without experiences of ELM and no history of mental disorder (HC: mean age $=39.57, \mathrm{SD}=4.27$ years). There was no significant age difference between the three groups. For details on mental disorders see table 1 .

The study was approved by the Ethics Committee of the Medical Faculty of the University of Heidelberg. All women signed a written informed consent after the study procedures had been explained and they received a financial compensation for their participation. 
Table 1. Mental disorders according to SCID-I in the nonresilient group $(\mathrm{n}=33)$

\begin{tabular}{|c|c|c|c|c|}
\hline & \multicolumn{2}{|c|}{ Current } & \multicolumn{2}{|c|}{ Lifetime } \\
\hline & $\mathrm{n}$ & $\%$ & $\mathrm{n}$ & $\%$ \\
\hline Major depressive episode & 1 & 3.03 & 23 & 69.70 \\
\hline Dysthymia & 1 & 3.03 & 0 & 0.00 \\
\hline Suicide risk & 0 & 0.00 & 4 & 12.12 \\
\hline Hypomania & 0 & 0.00 & 1 & 3.03 \\
\hline Panic disorder without agoraphobia & 0 & 0.00 & 4 & 12.12 \\
\hline Agoraphobia without panic disorder & 1 & 3.03 & 0 & 0.00 \\
\hline Panic disorder with agoraphobia & 0 & 0.00 & 1 & 3.03 \\
\hline Obsessive-compulsive disorder & 0 & 0.00 & 1 & 3.03 \\
\hline Social phobia & 1 & 3.03 & 1 & 3.03 \\
\hline Posttraumatic stress disorder & 0 & 0.00 & 4 & 12.12 \\
\hline Alcohol addiction & 0 & 0.00 & 2 & 6.06 \\
\hline Alcohol abuse & 0 & 0.00 & 3 & 9.09 \\
\hline Substance addiction & 0 & 0.00 & 1 & 3.03 \\
\hline Anorexia nervosa & 0 & 0.00 & 3 & 9.09 \\
\hline Bulimia nervosa & 0 & 0.00 & 3 & 9.09 \\
\hline $\begin{array}{l}\text { Anorexia nervosa binge-eating/ } \\
\text { purging type }\end{array}$ & 0 & 0.00 & 2 & 6.06 \\
\hline Generalized anxiety disorder & 3 & 9.09 & 0 & 0.00 \\
\hline
\end{tabular}

Multiple mental disorders were possible: 15 (45.45\%) women had only 1 lifetime mental disorder, 12 (36.36\%) women had 2 lifetime mental disorders, 3 (9.09\%) women had 3 lifetime mental disorders, and 3 (9.09\%) women had 4 lifetime mental disorders. Please note that mental disorders were an exclusion criterion for the resilient women and $\mathrm{HC}$ group.

\section{Measures}

We used the Childhood Experience of Care and Abuse (CECA) Interview [24], a semistructured retrospective interview for the assessment of adverse childhood experiences, including physical and sexual abuse before the age of 18 years, as well as the assessment of resilience factors during childhood, such as relationship with peers, perceived loneliness, perceived inferiority, support, shyness, participation in organized regular social activity, housing problems, occupational qualification of mother and father, number of children in the original family, and financial difficulties. The interrater reliabilities of each of the 13 scales of the German version of the CECA Interview were satisfactory since all but 3 scales showed a $\kappa$ value higher than 0.71 [25]. Validity was also satisfactory since all correlation coefficients with the corresponding questionnaire were between $r=0.58$ and $r=0.78$ [25]. Current and lifetime Axis I and II disorders were assessed with the Structured Clinical Interview for Mental Disorders (SCID-I) [26] and the International Personality Disorder Examination (IPDE) [27]. Interrater reliability for Axis I diagnoses in the SCID-I is reported to be moderate to excellent with $\kappa$ values between 0.61 and 0.83 for the different diagnoses [28]. Interrater reliability for the IPDE was about the same as in instruments used to diagnose psychoses, mood, anxiety, and substance use disorders [29]. No exact validity is reported for the IPDE [30] or SCID-I, but overall semistructured interviews have proven good validity [31]. Furthermore, emotion dysregulation

Resilience Factors in Women with Severe

Early-Life Maltreatment was assessed with the Difficulties in Emotion Regulation Scale (DERS) [32], a self-report questionnaire with a high internal consistency of $\alpha=0.93$. Vulnerable attachment was assessed with the Vulnerable Attachment Style Questionnaire (VASQ) [33]. The total score of VASQ had a correlation of $r=0.65$ at retest [33]. Impulsivity was assessed with the Barratt Impulsiveness Scale (BIS, version 11, German version) [34]. The total score of the BIS has a sufficient internal consistency with $\alpha=0.69$ [35]. The NEO FiveFactor Inventory (NEO-FFI) [36] was used to assess the personality facets 'neuroticism' and 'extraversion'. Both scales had a good internal consistency, neuroticism with $\alpha=0.86$ and extraversion with $\alpha=0.81$ [37]. Intelligence was estimated with the MultipleChoice Vocabulary Intelligence Test (MWT-B) [38], which assesses verbal intelligence in adults. Demographic data, including years of education, were assessed with a self-administered interview.

\section{Data Analyses}

Data were analyzed with IBM SPSS version 22. Across variables, $8.03 \%$ of all values were missing. Therefore, missing values were substituted with an average of 20 multiple imputations [39] (Rubin's Rule [40]), allowing the use of all 89 cases for further analyses.

\section{Factor Analyses}

In a first step, a principal axis factor analysis with varimax rotation was computed including the variable 'group' and 18 possible resilience variables identified in previous studies (table 2). The aim of this analysis was to detect variables loading high on the same factors as the group variable. We then performed a second factor analysis which included the same 18 resilience variables but without the group variable to generate factor scores of the identified factors. The scree plot criterion was used to determine the number of extracted factors. The sample size was good [41] with $n=89$ and Kaiser-Meyer-Olkin $=0.74$.

$\mathrm{t}$ Tests

The identified factors of the second factor analysis were submitted to two-sample $t$ tests (two-tailed $p<0.05$; Cohen's d as effect sizes) to investigate differences in the factor scores between the three groups (HC, resilient, and nonresilient).

\section{Discriminant Analysis}

Variables which differentiated the three groups best according to the factor analysis and tests ('relevant resilience variables') were submitted to a discriminant analysis to examine the accuracy of assigning women to the $\mathrm{HC}$, resilient, and nonresilient groups with the help of these relevant resilience variables.

\section{Results}

\section{Factor Analyses}

The scree plot justified retaining three factors explaining $52.35 \%$ of the total variance. Table 2 shows the factor loadings after varimax rotation. The group variable loaded highly $(r \geq|0.30|)$ on factors 1 and 3. Resilience variables which loaded highly on factor 1 were vul- 
Table 2. Factor loadings of the main factor analysis after varimax rotation

\begin{tabular}{|c|c|c|c|}
\hline & \multicolumn{3}{|l|}{ Factor } \\
\hline & 1 & 2 & 3 \\
\hline Group & 0.51 & -0.11 & -0.63 \\
\hline \multicolumn{4}{|l|}{ Current individual attributes } \\
\hline Vulnerable attachment style & 0.84 & -0.18 & -0.19 \\
\hline Neuroticism & 0.84 & -0.12 & -0.30 \\
\hline Emotional dysregulation & 0.80 & -0.07 & -0.16 \\
\hline Extraversion & -0.74 & 0.30 & 0.15 \\
\hline Impulsivity & 0.72 & -0.11 & 0.04 \\
\hline \multicolumn{4}{|l|}{ Social experiences in childhood } \\
\hline Relationship with peers during childhood & 0.09 & -0.06 & -0.77 \\
\hline Perceived loneliness during childhood & -0.10 & 0.18 & 0.73 \\
\hline Perceived inferiority during childhood & -0.20 & -0.11 & 0.69 \\
\hline Support during childhood & -0.29 & 0.36 & 0.54 \\
\hline Shyness during childhood & 0.08 & -0.19 & 0.51 \\
\hline Participation in organized regular social activity & 0.12 & -0.33 & -0.48 \\
\hline \multicolumn{4}{|c|}{ Familial, educational, and financial situation during childhood } \\
\hline Occupational qualification of the father & -0.12 & 0.73 & 0.06 \\
\hline Years of education & -0.27 & 0.65 & -0.05 \\
\hline Total number of children in the original family & -0.23 & -0.60 & -0.13 \\
\hline Intelligence & -0.25 & 0.57 & -0.10 \\
\hline Occupational qualification of the mother & -0.12 & 0.56 & -0.12 \\
\hline Housing problems during childhood & -0.11 & 0.54 & 0.25 \\
\hline Financial difficulties during childhood & -0.16 & 0.51 & 0.31 \\
\hline
\end{tabular}

The highest loading of each variable is italicized. In the variable 'group' all loadings over 0.30 are italicized. In the CECA Interview high values stand for 'little/none' and low values stand for 'marked'.

nerable attachment style, neuroticism, emotional dysregulation, extraversion, and impulsivity $(\mathrm{r} \geq|0.71|)$, which might thus be named as the women's 'current individual attributes'. High values on factor 1 indicate that the individual showed a highly vulnerable attachment style, high levels of neuroticism, high levels of emotional dysregulation, low levels of extraversion, and high levels of impulsivity. The variables related to childhood included relationship with peers, perceived loneliness, perceived inferiority, support, shyness, and participation in organized regular social activities; they had high loadings on factor $3(\mathrm{r} \geq|0.47|)$, which might thus describe 'social experiences in childhood'. High values on factor 3 indicate that the individual reported a high number of relationships with peers, low levels of perceived loneliness, low levels of perceived inferiority, high levels of support, low levels of shyness, and high levels of participation in organized regular social activity during childhood. The group variable did not load highly on factor 2. Variables which loaded highly on factor 2 were occupational qualification of the father, years of education, total number of children in the original family, intelligence, occupational qualification of the mother, housing problems during childhood, and financial difficulties during childhood $(\mathrm{r} \geq|0.51|)$, and may thus be considered as the 'familial, educational, and financial situation during childhood'. High values on factor 2 indicate that the individual reported a high occupational qualification of the father, a high number of years of education, a small number of children in the original family, a high level of intelligence, a high occupational qualification of the mother, few housing problems during childhood, and low levels of financial difficulties during childhood. Taken together, factor 1 (current individual attributes) and factor 3 (social experiences in childhood) may be important in differentiating between the $\mathrm{HC}$, resilient, and nonresilient groups and may thus be regarded as relevant resilience variables, while this does not seem to be the case for factor 2 (familial, educational, and financial situation during childhood). The factor loadings were confirmed in the second factor analysis, which did not include the variable group. 
$t$ Tests on Factor Scores of the Second Factor Analysis

Resilient Compared to Nonresilient Women

Resilient women had significantly smaller mean factor 1 scores (current individual attributes: mean $=-0.03$, $\mathrm{SD}=1.09$ ) compared to nonresilient women (mean = $0.57, \mathrm{SD}=0.92, \mathrm{t}(50)=-2.13, \mathrm{p}=0.038, \mathrm{~d}=0.56)$. However, the two groups did not significantly differ with regard to mean factor 3 scores (social experiences in childhood: $\mathrm{t}(50)=1.31, \mathrm{p}=0.196, \mathrm{~d}=-0.35)$. The groups did not significantly differ with regard to factor 2 (familial, educational, and financial situation during childhood: $\mathrm{t}(50)=0.96, \mathrm{p}=0.340, \mathrm{~d}=-0.26)$.

\section{Resilient Compared to HC Women}

Resilient women had significantly smaller mean factor 3 scores (social experiences in childhood: mean $=-0.22$, $\mathrm{SD}=1.02)$ than HCs (mean $=0.63, \mathrm{SD}=0.69, \mathrm{t}(54)=3.71$, $\mathrm{p}<0.001, \mathrm{~d}=-1.24)$. Resilient women tended to have a greater mean factor 1 score (current individual attributes: mean $=-0.03, \mathrm{SD}=1.09$ ) than HCs (mean $=-0.50, \mathrm{SD}=$ $0.74, \mathrm{t}(54)=-1.90, \mathrm{p}=0.063, \mathrm{~d}=0.63)$. Again, there was no significant difference in factor 2 (familial, educational, and financial situation during childhood: $\mathrm{t}(54)=0.15$, $\mathrm{p}=0.885, \mathrm{~d}=-0.04)$.

\section{Nonresilient Compared to HC Women}

Nonresilient women had greater factor 1 scores (current individual attributes: mean $=0.57, \mathrm{SD}=0.92$ ) and smaller factor 3 scores (social experiences during childhood: mean $=-0.58, \mathrm{SD}=0.89$ ) compared to HCs (factor 1 : mean $=-0.50, \mathrm{SD}=0.74$; factor 3 : mean $=0.63, \mathrm{SD}=$ 0.69 ). The difference was significant for factor 1 (current individual attributes: $\mathrm{t}(68)=-5.38, \mathrm{p}<0.001, \mathrm{~d}=1.45$ ) and factor 3 (social experiences in childhood: $\mathrm{t}(68)=6.39$, $\mathrm{p}<0.001, \mathrm{~d}=-1.76)$. The groups did not differ in factor 2 scores (familial, educational, and financial situation during childhood: $\mathrm{t}(68)=1.36, \mathrm{p}=0.179, \mathrm{~d}=-0.32$ ).

\section{Discriminant Analysis}

The 11 relevant resilience variables which were identified by high loadings on either factor 1 or 3 in the factor analysis (see above) were all entered together into a discriminant analysis. We used group-specific covariance matrixes since the Box $M$ test was significant. The variable shyness during childhood had to be removed because of low loadings on any of the discriminant functions, leaving 10 relevant resilience variables in the discriminant analysis. This analysis revealed two discriminant functions: the first function explained $96.6 \%$ of the variance (canonical $\mathrm{R}^{2}=0.66$ ) while the second

Resilience Factors in Women with Severe Early-Life Maltreatment

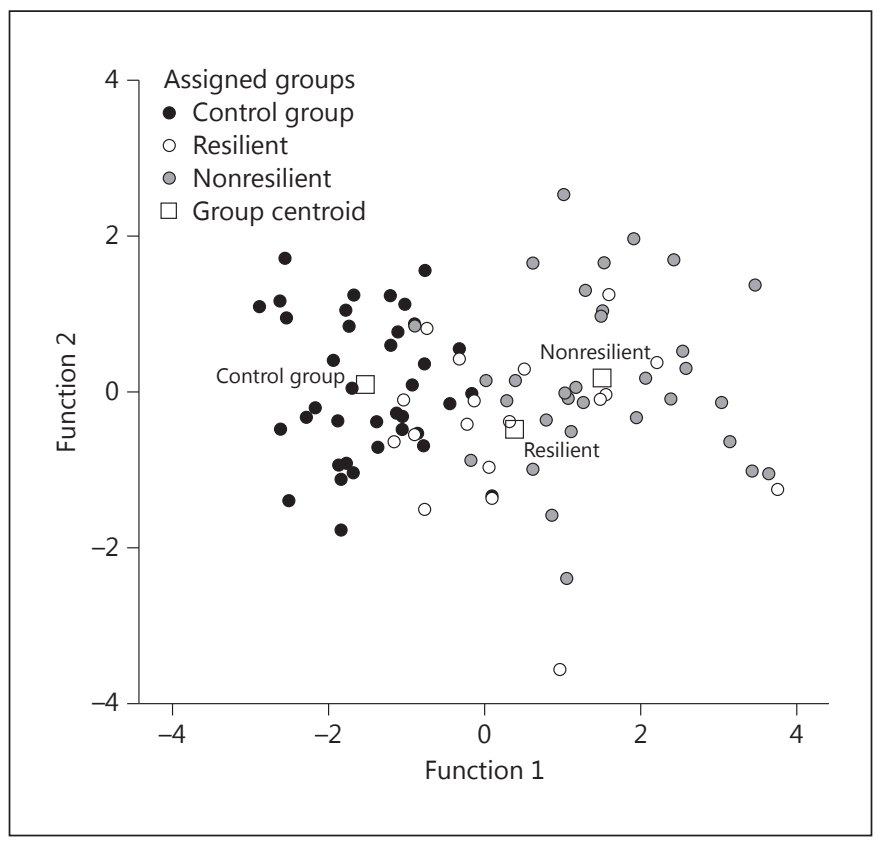

Fig. 1. Plot of canonic discriminant functions.

function explained $3.4 \%$ of variance (canonical $\mathrm{R}^{2}=$ 0.06). Using both discriminant functions together, we were able to significantly differentiate the three groups $\left(\Lambda=0.32, \chi^{2}(20)=92.32, p<0.001\right)$. However, when the first function was removed, the second function alone was not able to significantly differentiate the three groups $\left(\Lambda=0.94, \chi^{2}(9)=5.31, p=0.807\right)$. The 'relevant resilience variables' neuroticism $\left(\mathrm{r}_{1}=0.63, \mathrm{r}_{2}=0.40\right)$, perceived loneliness during childhood $\left(\mathrm{r}_{1}=-0.52, \mathrm{r}_{2}=\right.$ $0.36)$, vulnerable attachment style $\left(r_{1}=0.38, r_{2}=0.31\right)$, and extraversion $\left(\mathrm{r}_{1}=-0.39, \mathrm{r}_{2}=-0.40\right)$ loaded high on both discriminant functions, while support during childhood $\left(\mathrm{r}_{1}=-0.45, \mathrm{r}_{2}=0.24\right)$, emotional dysregulation $\left(r_{1}=0.40, r_{2}=-0.08\right)$, relationship with peers during childhood $\left(r_{1}=0.38, r_{2}=0.24\right)$, and perceived inferiority during childhood $\left(\mathrm{r}_{1}=-0.32, \mathrm{r}_{2}=0.08\right)$ had only high loadings on the first discriminant function, and participation in organized regular social activities $\left(\mathrm{r}_{1}=\right.$ $\left.0.22, \mathrm{r}_{2}=0.65\right)$ as well as impulsivity $\left(\mathrm{r}_{1}=0.29, \mathrm{r}_{2}=0.51\right)$ only loaded highly on the second discriminant function. The plot of the discriminant functions in figure 1 showed that the first function mainly discriminated HCs from nonresilient women, while the second function discriminated resilient women from both HCs and nonresilient women.

Most importantly, the combination of both discriminant functions was able to correctly classify $78.7 \%$ of 
women: $97.3 \%$ of HCs were assigned to the HC group and $2.7 \%$ to the resilient group; $36.8 \%$ of resilient women were assigned to the resilient group, $31.6 \%$ to the HC group, and $31.6 \%$ to the nonresilient group, and $81.8 \%$ of nonresilient women were assigned to the nonresilient group, $3.0 \%$ to the HCs, and $15.2 \%$ to the resilient group.

\section{Discussion}

The current study investigated resilience factors, i.e. variables that are able to differentiate resilient women from nonresilient as well as from healthy women. To achieve this, we collected self-report and interview-based data on 18 variables that have been identified in previous studies as potential resilience variables belonging to the three categories: individual attributes, the individual's childhood family, and the individual's wider social environment during childhood [4]. Using factor analysis, we were able to confirm a three-factorial structure. However, some of the collected variables loaded highly on a different factor than expected. We therefore decided to use somewhat different factor names than in a previous publication by Luthar et al. [4]. Differences between the current results and the findings of Luthar et al. might at least partly be attributable to age differences in the investigated samples, since Luthar et al. examined samples with children while the current study examined a sample of adult women.

Also, the group variable only loaded highly on two of the identified factors, 'current individual attributes' and 'social experiences in childhood', but not on a third factor comprising the 'familial, educational, and financial situation during childhood'. Thus only two of these factors were able to significantly differentiate resilient from nonresilient and $\mathrm{HC}$ women, as shown by the results of the two-sample $\mathrm{t}$ tests.

The two-sample $t$ tests revealed that all three groups significantly differed with regard to the factor scores on 'current individual attributes'. Consistent with our a priori hypothesis, nonresilient women scored significantly higher on these negative 'current individual attributes' compared to both resilient and HC women, therefore suggesting an individual profile of secure attachment, low levels of neuroticism, emotional dysregulation, and impulsivity as relevant for staying mentally healthy despite ELM [for similar results, see 7, 14, 16, 18]. However, contrary to our expectations, resilient women also tended to score higher on these negative 'current individual attributes' compared to $\mathrm{HC}$ women. This result may in- dicate a general negative influence of ELM on individual attributes. In addition, HCs scored higher on 'social experiences in childhood' compared to both resilient and nonresilient women. Again, this result is consistent with the severe impact ELM has on an individual's life as the factor consisted of a pattern of fewer relations with peers, greater perceived loneliness, inferiority, and shyness during childhood as well as less support and participation in organized regular social activities in women with ELM. Children who suffer from ELM are often brought up in an overall more negative, less stable, and less empathetic environment $[42,43]$. For the purpose of the current research question, it is interesting to note that a more positive pattern of 'current individual attributes' may be a more important factor for mental health throughout early and middle adulthood and thus resilience, while more negative 'social experiences in childhood' and 'current individual attributes' may both be a consequence of ELM.

Since 'social experiences in childhood' is an important factor for discriminating HCs from resilient and nonresilient women, the question about experienced emotional abuse during childhood arises. A study of Spertus et al. [44] showed that a history of emotional abuse is associated with increased physical and psychological symptoms in women (even after controlling for sexual and physical abuse). As effects of emotional abuse were not a primary topic of the present study, only 9 of the 89 women (10.11\%) reported moderate to severe emotional abuse in the CECA Interview, preventing an additional investigation of effects of emotional abuse in the current study.

In total, we are able to confirm 10 of the 18 proposed resilience factors. In the discriminant analysis, 4 of these variables (neuroticism, extraversion, vulnerable attachment, and perceived loneliness during childhood) loaded highly on both discriminant functions and may therefore be regarded as the most important negative predictors for resilience and discriminators between the three examined groups. Interestingly, these 4 variables contain aspects of social relationships in childhood as well as of individual attributes in a sense of individual traits, which may in turn affect social relationships [45]. It seems as if the interaction between individual traits and social relationships is very important for the differentiation of resilient, nonresilient, and $\mathrm{HC}$ women in the context of ELM.

With regard to the results of the discriminant analysis, it is also important to note that almost $97 \%$ of $\mathrm{HCs}$ and almost $82 \%$ of nonresilient women were correctly classified into their groups, while the assignment of the 
resilient group was more difficult with only $37 \%$ of correct classifications. Following the results of the discriminant analysis as well as the hypothesized process of reintegration by Richardson [6], one could assume that about one third of the resilient women may have experienced a resilient reintegration after ELM. Another third of the women in the resilient group may have reintegrated with loss and, despite the absence of lifetime mental disorders at middle adulthood, may share some individual traits and early-life social experiences partly similar to the nonresilient women. Finally, one third of the resilient women may have reintegrated back to homeostasis and may therefore significantly differ from both HCs and the nonresilient women in terms of individual traits and social experiences in childhood. Another aspect to consider concerns individual differences prior to the ELM both with regard to genetically driven vulnerability or susceptibility factors and to the social environment $[42,46]$.

The current study therefore raises important questions with regard to the development of new prevention and (early) intervention strategies. Prevention and intervention programs supporting the development of secure attachment and social competence as well as programs involving families and a child's broader social environment may be of particular importance for individuals with ELM. Whether prevention or intervention programs can modulate neuroticism and extraversion remains speculative at this stage of knowledge as these temperamental factors are thought to be highly stable and genetically driven.

\section{Limitations}

The study has several limitations. First, due to the crosssectional design, no statements regarding the causality can be made. Second, it was not monitored whether the women had any other severe experiences in their life besides ELM, i.e. in later life. However, it has to be noted that symptoms of posttraumatic stress disorder were covered by the SCID-I interview. Third, a retrospective interview, the CECA, was used to assess ELM without an objective control measure. However, the criteria of the CECA Interview have clear thresholds and focus on objective behaviors and not an individual's subjective feelings [24], which prevent incorrect classifications and increase interrater reliabilities. Fourth, multiple imputation with a high number of imputations was used to correct the high number of missing values (8.03\%) across all variables, which, despite being one of the best methods to deal with missing values, contains a certain risk of biasing the substituted data.

\section{Conclusion}

From the previously suggested 18 resilience factors, we were able to confirm 10 factors in the current study. Of these, 4 factors (neuroticism, extraversion, vulnerable attachment, and perceived loneliness during childhood) were identified as the most important factors for differentiating resilient women from HCs and nonresilient women. Interestingly, a positive pattern of current individual attributes turned out to be most significant for mental health through early and middle adulthood.

\section{References}

-1 Hauser W, Schmutzer G, Brahler E,Glaesmer $\mathrm{H}$ : Maltreatment in childhood and adolescence: results from a survey of a representative sample of the German population. Dtsch Arztebl Int 2011;108:287-294.

$\checkmark 2$ Hillberg T, Hamilton-Giachritsis C, Dixon L: Review of meta-analyses on the association between child sexual abuse and adult mental health difficulties: a systematic approach. Trauma Violence Abuse 2011;12:38-49.

-3 Augoustinos M: Developmental effects of child abuse: recent findings. Child Abuse Negl 1987;11:15-27.

4 Luthar SS, Cicchetti D, Becker B: The construct of resilience: a critical evaluation and guidelines for future work. Child Dev 2000; 71:543-562.
5 Jaffee SR: Social, emotional, and academic competence among children who have had contact with child protective services: prevalence and stability estimates. J Am Acad Child Adolesc Psychiatry 2007;46:757-765.

$\checkmark 6$ Richardson GE: The metatheory of resilience and resiliency. J Clin Psychol 2002;58:307321.

$\checkmark 7$ Collishaw S, Pickles A, Messer J, Rutter M, Shearer C, Maughan B: Resilience to adult psychopathology following childhood maltreatment: evidence from a community sample. Child Abuse Negl 2007;31:211-229.

$>8$ Frodi A, Smetana J: Abused, neglected, and nonmaltreated preschoolers' ability to discriminate emotions in others: the effects of IQ. Child Abuse Negl 1984;8:459-465. $\checkmark 9$ Zimrin H: A profile of survival. Child Abuse Negl 1986;10:339-349.

10 Werner EE: The children of Kauai: resiliency and recovery in adolescence and adulthood. J Adolesc Health 1992;13:262-268.

$\checkmark 11$ Rew L, Taylor-Seehafer M, Thomas NY, Yockey RD: Correlates of resilience in homeless adolescents. J Nurs Scholarsh 2001;33: 33-40.

12 Chen X, Wang L, Wang Z: Shyness-sensitivity and social, school, and psychological adjustment in rural migrant and urban children in China. Child Dev 2009;80:1499-1513.

13 Humphreys J: Resilience in sheltered battered women. Issues Ment Health Nurs 2003;24: $137-152$. 
14 Carli V, Mandelli L, Zaninotto L, Alberti S, Roy A, Serretti A, Sarchiapone M: Trait-aggressiveness and impulsivity: role of psychological resilience and childhood trauma in a sample of male prisoners. Nord J Psychiatry 2014;68:8-17.

15 Schelble JL, Franks BA, Miller MD: Emotion dysregulation and academic resilience in maltreated children. Child Youth Care Forum 2010;39:289-303.

16 Campbell-Sills L, Cohan SL, Stein MB: Relationship of resilience to personality, coping, and psychiatric symptoms in young adults. Behav Res Ther 2006;44:585-599.

$\checkmark 17$ Friborg O, Barlaug D, Martinussen M, Rosenvinge JH, Hjemdal O: Resilience in relation to personality and intelligence. Int $\mathrm{J}$ Methods Psychiatr Res 2005;14:29-42.

- 18 Karreman A, Vingerhoets AJ: Attachment and well-being: the mediating role of emotion regulation and resilience. Pers Individ Dif 2012;53:821-826.

19 Luthar SS: Methodological and conceptual issues in research on childhood resilience. J Child Psychol Psychiatry 1993;34:441-453.

20 DuMont KA, Widom CS, Czaja SJ: Predictors of resilience in abused and neglected children grown-up: the role of individual and neighborhood characteristics. Child Abuse Negl 2007;31:255-274.

-21 Davey M, Eaker DG, Walters LH: Resilience processes in adolescents: personality profiles, self-worth, and coping. J Adolesc Res 2003;18: 347-362.

-22 Feldman R, Vengrober A: Posttraumatic stress disorder in infants and young children exposed to war-related trauma. J Am Acad Child Adolesc Psychiatry 2011;50:645-658.

23 Clare M, Catherine H-G, Chris H: Factors promoting resilience following childhood sexual abuse: a structured, narrative review of the literature. Child Abuse Rev 2014;23:17.

-24 Bifulco A, Brown GW, Harris TO: Childhood Experience of Care and Abuse (CECA) - a retrospective interview measure. J Child Psychol Psychiatry 1994;35:1419-1435.

25 Kaess M, Parzer P, Mattern M, Resch F, Bifulco A, Brunner R: Childhood Experiences of Care and Abuse (CECA). Z Kinder Jugendpsychiatr Psychother 2011;39:243-252.
26 Wittchen H-U, Fydrich T: Strukturiertes Klinisches Interview für DSM-IV (SKID-I und SKID-II). Göttingen, Hogrefe, 1997.

27 Loranger AW, Mombour W (eds): IPDE: International Personality Disorder Examination; ICD-10 Modul. Bern, Huber, 1996.

28 Lobbestael J, Leurgans M, Arntz A: Inter-rater reliability of the Structured Clinical Interview for DSM-IV Axis I Disorders (SCID I) and Axis II Disorders (SCID II). Clin Psychol Psychother 2011;18:75-79.

29 Loranger AW, Sartorius N, Andreoli A, et al: The International Personality Disorder Examination: The World Health Organization/ Alcohol, Drug Abuse, and Mental Health Administration international pilot study of personality disorders. Arch Gen Psychiatry 1994; 51:215-224

30 Loranger AW, Janca A, Sartorius N: Assessment and Diagnosis of Personality Disorders: The ICD-10 International Personality Disorder Examination (IPDE). Cambridge, Cambridge University Press, 1997.

31 Margraf J, Schneider S (eds): Lehrbuch der Verhaltenstherapie. Band 1: Grundlagen, Diagnostik, Verfahren, Rahmenbedingungen. 3. vollständig bearbeitete und erweiterte Auflage (online resource - digital). Berlin/ Heidelberg, Springer, 2009.

32 Gratz KL, Roemer L: Multidimensional assessment of emotion regulation and dysregulation: development, factor structure, and initial validation of the Difficulties in Emotion Regulation Scale. J Psychopath Behav Assess 2004;26:41-54.

33 Bifulco A, Mahon J, Kwon JH, Moran PM, Jacobs C: The Vulnerable Attachment Style Questionnaire (VASQ): an interview-based measure of attachment styles that predict depressive disorder. Psychol Med 2003;33: 1099-1110.

34 Patton JH, Stanford MS, Barratt ES: Factor structure of the Barratt Impulsiveness Scale. J Clin Psychol 1995;51:768-774.
35 Preuss UW, Rujescu D, Giegling I, Watzke S, Koller G, Zetzsche T, Möller H-J: Psychometrische Evaluation der deutschsprachigen Version der Barratt-Impulsiveness-Skala. Nervenarzt 2008;79:305-319.

36 Costa P, McCrae RR: The NEO-PI/NEO-FFI Manual Supplement. Odessa, Psychological Assessment Resources, 1989.

37 Borkenau P, Ostendorf F: NEO-FFI: NEOFünf-Faktoren-Inventar nach Costa und McCrae: Manual. Göttingen, Hogrefe, 2008.

38 Lehrl S: Mehrfachwahl-Wortschatz-Intelligenztest: MWT-B; 5. Balingen, Spitta, 2005.

39 Graham JW, Olchowski AE, Gilreath TD: How many imputations are really needed? Some practical clarifications of multiple imputation theory. Prev Sci 2007;8:206-213.

40 Baltes-Götz B: Behandlung fehlender Werte in SPSS und Amos. Trier, Universitäts-Rechenzentrum Trier, 2013.

41 Hutcheson GD, Sofroniou N: The Multivariate Social Scientist: Introductory Statistics Using Generalized Linear Models. London, Sage, 1999.

42 Repetti RL, Taylor SE, Seeman TE: Risky families: family social environments and the mental and physical health of offspring. Psychol Bull 2002;128:330

43 Martin A, Najman JM, Williams GM, Bor W, Gorton E, Alati R: Longitudinal analysis of maternal risk factors for childhood sexual abuse: early attitudes and behaviours, socioeconomic status, and mental health. Aust NZ J Psychiatry 2011;45:629-637.

-44 Spertus IL, Yehuda R, Wong CM, Halligan S, Seremetis SV: Childhood emotional abuse and neglect as predictors of psychological and physical symptoms in women presenting to a primary care practice. Child Abuse Negl 2003; 27:1247-1258

45 Asendorpf JB, Wilpers S: Personality effects on social relationships. J Pers Soc Psychol 1998;74:1531-1544.

-46 Gutierrez B, Bellon JA, Rivera M, Molina E, King M, Marston L, Cervilla J: The risk for major depression conferred by childhood maltreatment is multiplied by BDNF and SERT genetic vulnerability: a replication study. J Psychiatry Neurosci 2015;40:187196.

\section{Erratum}

In the article by Hillmann K et al., entitled 'Resilience factors in women with severe earlylife maltreatment' [Psychopathology 2016;49:261-268, DOI: 10.1159/000447457], the following paragraph should be included before the references:

\section{Funding}

The study was part of the 'Understanding and Breaking the Intergenerational Cycle of Abuse' (UBICA) consortium supported by the German Federal Ministry of Education and Research (ID no.: 01KR1207A). 